\title{
Esparta e o Oriente entre os Períodos Arcaico e Clássico
}

\author{
Sparta and the East between the Archaic and Classical Periods
}

\section{Gabriel Cabral Bernardo*}

\begin{abstract}
Resumo: A história de Esparta é geralmente dividida entre os Períodos Arcaico e Clássico, caracterizados, respectivamente, pela abertura a influências externas e pelo posterior bloqueio dessas. Entretanto, uma análise mais cuidadosa da relação entre Esparta e o Oriente Próximo pode mostrar, nesses dois períodos, um continuum e não fases completamente diferentes de uma mesma sociedade. Considerando a cultura material espartana e as evidências literárias dos períodos Arcaico e Clássico, temos um quadro em que Esparta manteve sim alguma inserção nas redes do Mediterrâneo oriental, mas indiretamente, associando-se a cidades ou agentes já bem estabelecidos nessas redes. Nesse sentido, Esparta não mudou completamente de atitude em relação às suas relações "internacionais", mas manteve a mesma lógica de conexão, investindo apenas na conectividade que respondia às suas demandas internas específicas.
\end{abstract}

\begin{abstract}
The history of Sparta is usually divided between the Archaic and Classical periods, these characterized, respectively, by openness to external influences and its subsequent blockage. However, a closer analysis of the relationship between Sparta and the Near East may show, in these two periods, a continuum rather than completely different phases of the same society. Considering the Spartan material culture and the literary evidences of the Archaic and Classical periods, we have a picture in which Sparta did maintain some insertion in the Eastern Mediterranean networks, but indirectly, associating itself with cities or agents already well established in these networks. In this sense, Sparta did not completely changed its attitude towards its "international" relations, but maintained the same logic of connection, investing only in the connectivity that responded to its specific internal demands.
\end{abstract}

\author{
Palavras-chave: \\ Esparta. \\ Mediterrâneo. \\ Conectividade. \\ Oriente Próximo.
}

\section{Keywords: Sparta. Mediterranean. Connectivity. Near East.}

\footnotetext{
* Doutorando em História Social pela Universidade de São Paulo (Usp) sob orientação do Prof. Dr. Norberto Luiz Guarinello. Bolsista da Fundação de Amparo à Pesquisa do Estado de São Paulo (Fapesp).
} 


\section{Introdução}

$\mathrm{D}$ esde a publicação de obras como The Orientalizing Revolution (1992), de Walter Burkert, é praticamente impossível estudar a Grécia antiga desconectando-a de suas relações com o Mediterrâneo oriental. O pós-colonialismo, inaugurado nos Estudos Clássicos por tais obras, abriu uma miríade de possibilidades que vêm sendo exploradas há pelo menos quatro décadas por classicistas com os mais diversos interesses e especialidades. Esse último processo, ao se deparar, primeiro, com os fenômenos da globalização e, mais recentemente, com o reforço de fronteiras internacionais, forneceu nuances muito mais bem definidas à relação mantida entre os habitantes do Mar Egeu e os de outras localidades do Mediterrâneo. Com isso, mostrou-se que não é mais suficiente apenas inverter o fluxo, como se fazia na década de 1980 - isto é, "contrabalancear" a "helenização" do Oriente pela "orientalização" da Grécia na primeira metade do I milênio (DOUGHERTY; KURKE, 2003, p. 2-4). ${ }^{1}$ É necessário que cada caso seja analisado em seus próprios termos, isso antes de ser reinserido em um panorama mais amplo, a fim de que suas generalidades e particularidades sejam devidamente compreendidas.

Sabendo disso, vale notar que os termos que condicionaram a relação de Esparta com as redes mais amplas do Mediterrâneo ainda se encontram pouco estudados em algumas de suas especificidades, principalmente no que se refere à sua posição nos fluxos que ligavam o Mar Egeu e o Oriente Próximo. Além disso, tal problema é complicado ainda mais por um vício interno à própria produção bibliográfica sobre Esparta: a divisão de sua história em dois períodos, esses encarados como completamente distintos em relação à abertura da pólis a qualquer contato com povos externos à Lacônia. ${ }^{2}$ Enquanto a Esparta do Período Arcaico é representada como uma sociedade dinâmica e extremante aberta a produtos materiais e culturais de outros locais (COUDIN, 2009, p. 175), a Esparta do Período Clássico seria seu exato oposto. A chamada "Reforma de Licurgo", realizada em meados do século $\mathrm{VI}$ - que formou a Esparta mais conhecida, a militarizada e oligárquica -, seria a mesma que causou a adoção, nos séculos seguintes, do isolamento como forma de manter intacto o estilo de vida que mantinha a "boa ordem" (eunomía) dentro da pólis. ${ }^{3}$ Tal ponto de vista condicionou uma bibliografia polarizada que vê, no

\footnotetext{
${ }^{1}$ Todos as datas relativas à Antiguidade aqui referidas são a.C., a menos que indicado.

2 Por "Lacônia" me refiro à região na qual Esparta se situava, que corresponde, resumidamente, ao sudeste do Peloponeso - da costa a leste do Monte Parnon ao vale do Rio Eurotas, a leste do monte Taígeto (Figura 1).

${ }_{3}^{3}$ Por exemplo, Stubbs (1950, p. 36); Holladay (1977, p. 10-11); Shipley (2009, p. 57, 58). Ver Figueira (2003, p. 48-62) sobre as fontes que caracterizam esse isolamento como um elemento da própria constituição espartana.
} 
Período Arcaico, diversos pontos de contato entre Esparta e o Oriente, mas praticamente nenhum na Esparta de Licurgo. Isso se deve, dente outros fatores, à busca por tais relações em fontes diferentes nos dois períodos: a análise da cultura material predomina nas investigações referentes ao Período Arcaico, enquanto que as fontes literárias, carregadas do supracitado discurso conservacionista da eunomía, praticamente monopolizam as interpretações sobre o Período Clássico.

Tais questões deixam claro que é necessária uma análise mais detida de tais fontes, consideradas sem a pressuposição de uma abertura total ou de um fechamento completo da Esparta que as produziu. Isso será feito aqui com dois objetivos específicos. O primeiro é o de reavaliar o nível e a natureza das conexões entre a Esparta arcaica e a de Licurgo e o mundo mediterrânico oriental, mais especificamente durante os séculos VII a V. Tal análise fornecerá a base analítica do segundo objetivo: a crítica da suposta dissolução das conexões entre Esparta e redes mais amplas, isso no contexto da passagem do Período Arcaico para o Clássico. Veremos que em ambos os períodos Esparta manteve alguma ligação com o Oriente, essa nem sempre massiva (como em outros lugares do mundo grego) e talvez mediada por agentes intermediários que, em um segundo momento, adaptavam os elementos hoje vistos como "orientalizantes" às demandas específicas da Lacônia.

Com tais objetivos, tomo aqui três estudos de caso que constroem, juntos, a imagem de uma passagem mais fluida entre as "Espartas" arcaica e clássica, bem como entre as fontes arqueológicas e literárias. Dois deles lidam com categorias dos artefatos diferentes encontrados em um dos principais santuários espartanos, o de Ártemis Orthia, escavado pela Escola Britânica de Atenas no começo do século XX. O primeiro se refere aos marfins gravados e esculpidos, dedicados no santuário do final do século VIII ao começo do VI. O segundo se refere às máscaras de terracota encontradas em estratos que vão do século VII ao começo do V. Por fim, considerarei o uso espartano, no século V, da tinta púrpura de fabricação fenícia. Creio que será possível, por meio dessa amostragem, observar como a relação de Esparta com culturas ou entidades políticas do Oriente Próximo não passou por mudanças quantitativas bruscas (como a bibliografia parece afirmar, mesmo que involuntariamente), mas sim, abriga focos qualitativos diferentes em momentos distintos, seguindo demandas oriundas de disputas mais próximas à Lacônia e à sua própria zona de influência mais imediata. Antes disso, entretanto, é necessário considerar alguns pontos-chave da história espartana do Período Arcaico. 


\section{Marfins e a expansão interna (e externa) de Esparta}

Chester Starr (2002) notou, ${ }^{4}$ há mais de meio século, que grande parte do que sabemos sobre o Período Arcaico espartano por meio das fontes literárias desse período é, no mínimo, fragmentário e alusivo. Por sua vez, as narrativas contidas em fontes do Período Clássico, compostas séculos depois, dizem mais sobre o presente em que foram construídas do que sobre o passado arcaico do qual falam (EHRENBERG, 2011, p. 22). Sendo assim, não se mantém até hoje um consenso sólido entre os especialistas sobre como ocorreu a formação da Esparta arcaica. Sabemos da existência de assentamentos densos na Lacônia da Idade do Bronze, ${ }^{5}$ e que o suposto despovoamento da região na Idade do Ferro é uma ideia mais baseada nas poucas informações arqueológicas resgatadas do que na inexistência dessas (CAVANAGH, 2020, p. 649-658). De qualquer forma, o elemento mais significativo da história arcaica de Esparta é sua ligação com o mito do retorno dos Heráclidas, isto é, a marcha que os descendentes de Héracles empreenderam, sob a liderança dos dórios, para o Peloponeso e para as regiões que seu antepassado epônimo havia conquistado (Tucídides, 1, 12, 3). Há opiniões diferentes sobre esse caso, havendo quem leia a imigração dórica como algo arqueologicamente comprovável (EDER, 1998) e quem a entenda como um "mito de fundação", constantemente reconstruído do século VIII ao V (HALL, 1997, p. 56-65; 184-185).

Fundada Esparta, temos as duas Guerras Messênias como os primeiros eventos significativos minimamente traçáveis na história da pólis. Entretanto, ainda não se chegou a um consenso sobre sua datação. Se seguirmos os referenciais providos por Pausânias, o primeiro enfrentamento teria ocorrido talvez no final do século VIII e o segundo, fruto de uma revolta, nas primeiras décadas do século VII (cf. NAFISSI, 2009, p. 120-121). Por outro lado, há quem acredite que tais datas se baseiam em listas dos reis espartanos editadas até a época de Pausânias, nos séculos I e II d.C. Richer (2018, p. 27), por exemplo, adianta a Primeira Guerra Messênia para o primeiro quartel do século VII e a Segunda para as últimas décadas do mesmo século. Sabemos desses conflitos principalmente pelas obras sobreviventes de Tirteu (fr. 5, 4-8 West), poeta espartano do século VII. Entretanto, um processo talvez anterior ou mesmo paralelo deixou menos traços históricos: a submissão, por Esparta, das regiões costeiras da Lacônia, as mesmas que dariam um acesso mais facilitado às redes mediterrânicas que aqui me interessam. Vale lembrar, como foi dito anteriormente (nota 2 supra), que Esparta ficava entre duas cadeias de montanhas que a

\footnotetext{
${ }^{4}$ Publicação original de 1965.

${ }^{5}$ Ver, por exemplo, os artigos da primeira parte em Cavanagh, Gallou, Georgiadis (2009).
} 
isolavam do mar, sendo a saída mais rápida para esse ao Sul, em direção à antiga Gítio (moderna Gíthio). As hipóteses variam, datando o início do controle espartano sobre a planície de Helos (ao sul de Esparta, na foz do rio Eurotas) do século X (CARTLEDGE, 2002, p. 83-84) ao VIII (RICHER, 2018, p. 28-29). De fato, as fontes disponíveis impedem uma datação precisa desse evento, mas há algum consenso de que já no século VIII a região costeira mais fértil ao sul de Esparta estava sob seu domínio. Digo isso porque objetos de marfim, material impossível de se obter em qualquer região próxima à Lacônia, foram escavados em estratos desse período no santuário de Ártemis Orthia, em Esparta (DAWKINS, 1929a, p. 12; DAWKINS, 1929b, p. 203-204).

Obviamente, para que os espartanos tivessem acesso aos produtos do comércio marítimo não era uma condição sine qua non que Esparta mantivesse, já no século VIII, uma relação necessariamente de controle sobre a região costeira do sul da Lacônia. Ainda assim, o próprio contexto do depósito dos marfins indica não só a atividade de uma elite enriquecida, talvez pelas novas terras anexadas à jurisdição espartana (com certeza na Lacônia, talvez na Messênia), mas também, na passagem dos séculos IX e VIII, a construção do primeiro templo e de um novo altar no santuário de Orthia (DAWKINS, 1929a, p. 8-14). Ou seja, é plausível que o século VIII tenha testemunhado um enriquecimento de ao menos parte da população de Esparta. Mesmo que a Primeira Guerra Messênia tenha acontecido no período mais antigo proposto, no final do século VIII, ainda é mais plausível que esse primeiro enriquecimento tenha sido devido a uma expansão mais local de Esparta, provavelmente em direção ao Sul, ao restante das terras férteis do vale do rio Eurotas, à planície de Helos e, portanto, à costa norte do Golfo da Lacônia. Esse quadro nos provê de condições que podem explicar o uso e dedicação, pelos espartanos, dos objetos de marfim encontrados em Orthia de meados do século VIII até o final do século VII (DAWKINS, 1929b, p. 203-204).

Os objetos aos quais me refiro aqui incluem gravações em placas, estatuetas e selos, bem como gravuras em baixo relevo utilizadas para adornar móveis ou objetos pessoais. O marfim com o qual esses objetos eram feitos já era tido como uma matériaprima rara e de alto valor na região do Levante desde pelos menos o século IX (FELDMAN, 2015) - algo que provavelmente não era diferente em Esparta (ST. CLAIR, 2003, p. 21-22). Menciono aqui seu uso no Levante (incluindo a região do norte da Síria e toda a costa da Fenícia) porque é dali que provêm as maiores e mais antigas coleções dos objetos supracitados, o mesmo local onde se acredita terem sido desenvolvidos os estilos que posteriormente são levados ao Egeu (CARTER, 1985, p. 122-125). A definição desses estilos, algo já discutido por mais de um século, nos traz de volta à questão que nos interessa as possíveis relações mantidas entre Esparta e o Oriente no Período Arcaico. Os marfins 
encontrados em Orthia, dentro de sua variedade de temas e formatos, já foram atribuídos a um dos estilos delimitados no Levante, mais especificamente o estilo do norte da Síria.

Vale dizer que a bibliografia mais recente já pôs uma série de críticas sobre a suposta solidez desses estilos, mas uma longa exposição sobre tal debate não contribuiria muito para o raciocínio aqui proposto (cf. AFFANNI, 2009; SUTTER, 2015). Basta dizer, portanto, que os dois estilos básicos que dividem os marfins levantinos são o já citado do norte da Síria e o fenício. O primeiro, caracterizado por figurações com proporções maiores e de aparência mais rústica e, o segundo, pela presença marcante de elementos iconográficos egípcios, bem como pela maior delicadeza dos traços e de organização das figurações (cf. WINTER, 1976).

Os estilos mencionados não seriam completamente contemporâneos: o do norte da Síria teria surgido antes, no século IX, sendo produzido ao lado do estilo fenício no século VIII e desaparecendo antes desse, talvez no início do século VII (WINTER, 1976, p. 15-16). ${ }^{6}$ Um ponto interessante dos debates mais recentes sobre tais estilos é a identificação de um terceiro, chamado também de "intermediário" por incluir elementos dos estilos fenício e do norte da Síria. ${ }^{7}$ Isso, por si só, revela que, mesmo no centro produtor dos marfins, a adaptação das figurações a demandas locais não era algo impensável. Nesse sentido, há duas hipóteses que explicariam o caso espartano, e ambas defendem uma posição secundária de Esparta na cadeia de transmissão da técnica de gravação em marfim.

Uma das hipóteses é a de que os marfins espartanos, bem como seu estilo local, teriam sido compostos por elementos do Levante levados a Esparta através de Samos (MARANGOU, 1969; CARTER, 1985, p. 72-73; 78-157). A Arqueologia, bem como fontes posteriores (mais especificamente, Heródoto 3,47), parecem deixar entrever uma relação comercial/política relativamente próxima entre a Lacônia e Samos durante o Período Arcaico, talvez desde o começo do século VII. ${ }^{8}$ Não se nega aqui a existência dessa relação, mas, como vimos acima, objetos de marfim aparecem em Esparta antes dos primeiros indícios de contato entre as duas regiões - datados, na melhor das hipóteses, do final do século VIII (cf.FRAGKOPOULOU, 2012, n. 7). Sendo assim, podemos nos voltar para a segunda hipótese levantada.

Kostantinos Kopanias (2009) nota que parte do estilo identificado em Esparta, ainda que carregue elementos do norte da Síria, já se mostra adaptado ao gosto "helênico", com vestes, joias e cenas mitológicas locais. Segundo Kopanias, os marfins espartanos

\footnotetext{
${ }^{6}$ Para uma revisão da história arqueológica: Herrmann; Laidlaw; Coffey (2009, p. 27-29).

7 Ver Winter (1981); Gansell et al. (2014, p. 195-197) com bibliografia; Sutter (2015, fig. 1) para um infográfico extremamente claro sobre estilos e seus subgrupos.

${ }^{8}$ Ver Carter (1985, p. 93; 112) n. 84 (perirrhanteria de mármore encontrados em Samos, provavelmente advindos da Lacônia); Cartledge (1977); Shipley (1987, p. 55-56); Pipili (1998, p. 82-96) e Stibbe (1997) para a cerâmica; Fragkopoulou (2012).
} 
seriam derivados de um segundo movimento de recepção dos marfins levantinos. Esses últimos, tendo aportado em Creta no século VIII, tomam traços locais antes de atraírem a clientela espartana. Esse modelo de interpretação condiz com estudos mais recentes sobre as possíveis rotas de comércio fenícias, que passavam preferencialmente por Creta ao invés de enfrentar os ventos e correntes cambiantes do sul do Egeu (PUCKETT, 2012, p. 54-56; 96-97; 105-109). De qualquer forma, a demanda espartana teria atraído não só os produtos cretenses em marfim, mas também os próprios artesãos: há peças, escavadas no santuário de Orthia, que se encontram inacabadas, o que atesta uma produção local provavelmente associada ao sítio (ST. CLAIR, 2003, p. 19; 23; cf. DAWKINS, 1929b, pls. CVI, 3; CXVI, 1; CXVI, 2). Somemos a isso a identificação, nas peças espartanas, de uma "evolução" estilística, essa temporalmente coerente com um processo de refino das técnicas ali empregadas (DAWKINS, 1929b, p. 245).

A presença de oficinas locais de gravação de marfins indica, por conseguinte, demanda pela própria matéria-prima do marfim. Nesse sentido, é necessário dizer que, dentro da categoria dos objetos supracitados, os feitos de marfim são a menor parte da coleção obtida no santuário de Orthia. A maioria ainda é de ossos metapodais bovinos, material de obtenção fácil e, portanto, provavelmente menos custoso (ST. CLAIR, 2003, p. 19). Obviamente, sendo o marfim um material mais sensível, é possível que vários exemplares desse material tenham sido perdidos - principalmente em um local como o santuário de Orthia, sob constante ameaças de enchentes pelo rio Eurotas. Ainda assim, dadas as condições de escavação do santuário, acredita-se que as proporções não fossem muito diferentes das que conhecemos hoje, o que indica que a obtenção do marfim não foi facilitada a ponto de fazer desnecessária a produção em osso. Creio ser impossível traçar exatamente os canais pelos quais os artesãos espartanos obtinham marfim, mas podemos supor que, pelo custo aparente, não fosse por meio de uma conexão direta com seus fornecedores. Sabemos apenas que esse fornecimento cessa por volta de 600, período que inaugura uma série residual de objetos em osso, isso antes da dedicação desses cessar completamente - o que indica que a demanda pelos objetos não deixou de existir até pelo menos o começo do século V (DAWKINS, 1929b, p. 203-204).

São duas as principais teorias levantadas para a interrupção da presença do marfim no santuário, e ambas apontam para problemas de fornecimento no Levante. Uma delas, recentemente discutida, é a de que os rebanhos de elefantes da Síria, talvez a principal fonte de marfim da região, deixam de ser produtivos entre os séculos VIII e VII (ÇAKIRLAR; IKRAM, 2016). Essa teoria dá uma margem mais imprecisa para sua adequação ao caso espartano, talvez mesmo requerendo um adiantamento da datação proposta para a interrupção da importação de marfim em Esparta. A segunda tem o efeito oposto: a 
interrupção seria mais recente, mais próxima das campanhas militares persas que arrasam a Fenícia (comerciante por excelência de marfim) no começo do século VI, talvez mesmo da destruição de Tiro em 574 (DAWKINS, 1929b, p. 203, 245).

São necessários mais estudos sobre a rede de comércio mediterrânica do marfim e dos objetos de marfim provenientes do Levante, de modo que respostas mais definitivas possam ser dadas a respeito de sua dinâmica entre os séculos VII e VI. De qualquer forma, com base nas interpretações atuais das fontes disponíveis, parece que Esparta, no início de sua expansão, construiu pontes primeiramente com cretenses ou outros gregos que já tinham adotado o uso e talvez a produção de objetos em marfim (cf. DAWKINS, 1929b, p. 245-248). A necessidade de tais objetos e a distinção social a eles atrelada teria levado ao estabelecimento de oficinas locais que, por sua vez, criaram uma demanda pelo marfim não trabalhado, esse, provavelmente, comercializado para o Mediterrâneo a partir do Levante. Ou seja, uma conexão mais direta com as regiões da Fenícia e norte da Síria, prováveis berços da técnica, se existia, só foi estabelecida em um segundo momento. Nesse sentido, Esparta parece ter sido, ainda no começo de sua história hegemônica, mais dependente de redes já consolidadas do que um dos nós centrais de alguma delas.

É possível que tal quadro tenha sofrido mudanças no século VII, quando Esparta já tinha solidificado seu controle da Messênia e das regiões vizinhas. Isso talvez possa estar impresso em outra série de objetos também escavados, principalmente, no santuário de Ártemis Orthia: as máscaras de terracota.

\section{Máscaras fenícias (?) em Esparta}

Das escavações da Escola Britânia foi encontrado um conjunto significativo de máscaras de terracota, essas representando vários tipos de figuras - faces grotescas em vários estilos, sátiros, górgonas e "retratos" masculinos. É quase certo que a maioria dessas máscaras não foi, de fato, utilizada, dada a sua forma achatada e a falta de furos nos olhos, nariz e boca (DICKINS, 1929, p. 174-175; cf. CAMPANELLA, 2009, p. 530). É mais provável que elas fossem réplicas das máscaras utilizadas originalmente, talvez feitas de materiais mais leves e melhor adaptadas ao uso em rituais sobre os quais nossas fontes não nos dizem nada. ${ }^{9}$ Sua datação, assim como a maior parte dos outros tipos de

\footnotetext{
${ }^{9}$ Robert C. Bosanquet (1905-6, p. 338-340) costura várias referências posteriores, de Estrabão a Hesíquio, na tentativa de conectar as máscaras de Orthia a rituais dedicados a Ártemis que envolviam a participação de homens travestidos de mulheres, mas aparentemente de um modo grotesco. Há vários problemas com essa interpretação. Primeiramente, não há indícios de máscaras femininas no conjunto escavado no sítio. Dickins (1929, p. 166-167), inclusive, na tentativa de forçar tal interpretação, identifica o tipo de máscara mais comum no santuário como representando "velhas", mesmo não enunciando nada que baseie indiscutivelmente tal identificação - algo muito criticado posteriormente, principalmente
} 
achados, depende de sua posição estratigráfica em meio às séries cerâmicas. Assim, Guy Dickins (1929, p. 163-164) data o início (relativamente tímido) da presença das máscaras de terracota no santuário de Orthia de logo antes de c. 600, com uma expressão mais significativa entre 600 e 550, seguida de exemplares residuais até o começo do século V, esses cada vez menores e menos trabalhados. John Boardman (1963, p. 2), ao propor outra datação para os conjuntos cerâmicos, sugere um enquadramento mais recente para o segundo momento das máscaras: o terminus post quem do maior número de exemplares seria em 570-560. Entretanto, Boardman não discute a datação do estilo cerâmico Lacônio III, em que foram encontradas as máscaras mais recentes. Assim, não é possível ajustar o terminus ante quem do número máximo de máscaras nos depósitos, ou mesmo a datação do término da série como um todo. Devemos nos contentar, portanto, com uma popularidade máxima das máscaras nas imediações de c. 550, com uma tradição que teria sido iniciada antes de 570-560.

Digo "iniciada" e não "inventada" porque, assim como os marfins, também as máscaras parecem ser provenientes de um contexto levantino, ou ao menos púnico. Máscaras de terracotta são encontradas no Levante desde ao menos meados do II milênio, ${ }^{10}$ nas colônias púnicas do Mediterrâneo ocidental desde os séculos VIII e VII, ${ }^{11}$ na mesma época em que elas teriam, teoricamente, chegado a Esparta e ao santuário de Orthia. O estudo de Jane B. Carter (1987) foi o primeiro a fazer a conexão entre as máscaras escavadas em Esparta e as provenientes de vários outros santuários do Mediterrâneo. Não seria muito profícuo aqui rever todos os posicionamentos da autora, que coloca críticas extremamente pertinentes aos arqueólogos britânicos. Me limito a dois pontos por ela enunciados que dizem respeito aos interesses desse artigo.

Um dos pontos notados por Carter (1987, p. 360-369) é a semelhança entre um tipo de máscara bem comum nos assentamentos púnicos mediterrânicos e o tipo de máscara mais antigo e mais comum em Orthia. Esse tipo é caracterizado por um rosto humano, ainda que grotesco em algum nível por conta da marcação exagerada do que é comumente descrito como rugas ao redor da boca, nariz e testa, quase sempre emoldurando por uma expressão "sorridente", com os dentes aparentes. Esse tipo de

pelo viés de gênero que se impõe às máscaras (cf. SUDDABY, 2017, p. 29). Isso mostra uma clara tentativa de adequar dados arqueológicos às fontes literárias, sem levar em conta que mesmo essa explicação não dá conta de todos os tipos de máscaras identificados (CARTER, 1987, p. 356-357). Além disso, a atribuição das máscaras a um culto a Ártemis esbarra no problema de que Orthia só é identificada com a deusa em meados do século I d.C. (CALAME, 1997, p. 168169). Para uma possível conexão entre as máscaras de Orthia e a prática teatral grega, ver Rosenberg (2015).

10 O exemplar mais antigo de uma máscara de argila é proveniente de Tell el-Far'ah, a antiga Tirzah (MALLET, 1987, p. 92, fig. 18.1, pl. LXXXI:1; ver De Miroschedji (1993, p. 434) para a datação.

${ }^{11}$ Por exemplo, o artefato encontrado em Morro de Mezquitilla, na Espanha (SCHUBART, 1984, p. 94). Um panorama completo sobre os vários tipos, tradições e cronologias das máscaras fenícias pode ser encontrado em Orsingher (2018). 
máscara, encontrada em exemplares cipriotas e levantinos, parece ter tido sua origem no Mediterrâneo Ocidental, talvez em Cartago, caracterizando-se como uma reelaboração que articulou elementos antes separados, mas já presentes na tradição coroplástica fenícia (ORSINGER, 2014, p. 148-149).

Segundo Carter (1987), as máscaras de terracota sorridentes, possivelmente traçáveis no registro arqueológico a partir de meados do século VII (cf. NIEMEYER, 2007, p. 762-3, n. 6143, pl. 49), teriam sido levadas para outras localidades do Mediterrâneo pelos fenícios ou púnicos ao lado do que Carter (1987, p. 366-370) chama de "máscaras de herói" (o contraponto original do monstro representado pelas máscaras "sorridentes"), com traços masculinos "idealizados" de jovens e adultos. Essas possuem paralelos menos exatos em Esparta, talvez porque nenhum exemplar assim caracterizado tenha sobrevivido inteiro. Sabendo disso, e que os outros tipos identificáveis em Orthia - as máscaras de Sileno e de Górgona - são provavelmente desenvolvimentos locais, a melhor chance que temos de traçar a origem do uso e produção das máscaras espartanas é por meio das do tipo "sorridente". Entretanto, ainda assim, é extremamente difícil traçar o exato desenvolvimento estilístico dessas: as máscaras mais próximas, esteticamente e temporalmente, das espartanas são ainda muito diferentes (cf. DICKINS, 1929, pl. XLVIIXLIX). Temos, por exemplo, um exemplar de Cartago, ${ }^{12}$ talvez da primeira metade do século VII, no qual é possível observar as rugas marcadas tanto na testa quanto nas bochechas, mas essas não são contínuas, como no caso das máscaras espartanas. ${ }^{13}$ O exemplar cartaginês deixa os dentes à mostra, mas não com detalhamentos individuais como os exemplares de Orthia. Os olhos púnicos são moldados em formato de meialua, enquanto que os espartanos são redondos. Levando em conta a cronologia dos desenvolvimentos das máscaras fenício-púnicas proposta por Adriano Orsingher (2014, p. 151-153, cf. fig. 3), não seria possível que a tradição espartana tenha começado muito depois do exemplar cartaginês. Isso pelo simples motivo que, nos assentamentos púnicofenícios, as máscaras mais recentes, que começam a aparecer na segunda metade do século VI, são ainda mais diferentes (cf. ORSINGHER, 2014, p. 151-152).

Essa dificuldade em definir uma única fonte de inspiração para as máscaras espartanas pode não ser, entretanto, o melhor caminho a ser seguido. Nesse ponto é possível introduzir o segundo aspecto que vale a pena destacar do artigo de Carter (1987, p. 378-383). Me refiro, mais especificamente, ao esforço que a autora despende em conectar múltiplos tipos de informações de modo que essas atestem que a presença

\footnotetext{
12 Museu do Louvre: AO 3242 - fotografia em Markoe (2000, p. 168, fig. 68). Também disponível no site do museu: <https://www.louvre.fr/en/oeuvre-notices/grimacing-mask>.

${ }^{13}$ Ver fotografias em: Dawkins (1929, pls. XLVII-XLIX, LIX.1, LXI.1, LXII.2).
} 
das máscaras no santuário de Orthia é devida à existência, dentro de Esparta, de uma comunidade fenícia (cf. MORRIS, 1992, p. 134-136). Tal comunidade não só teria fundado o culto a Orthia como uma variação da deusa fenícia Tanit, mas também várias práticas e iconografias "orientalizantes". Como vimos em relação aos marfins, os espartanos parecem (assim como todos os povos nas margens do Mediterrâneo), selecionar aquilo que lhes interessava de práticas e objetos estrangeiros - inclusive dando ou privilegiando notas locais ao estilo dos objetos ali consumidos e/ou produzidos. Talvez o mesmo possa ser dito das máscaras de terracota. Afinal de contas, no decorrer do século VI, quando as datações colocam a maior popularidade das máscaras em Orthia, temos também o ápice da importação de cerâmica lacônia, essa encontrada desde a púnica Huelva, na Espanha, até a fenícia Al-Mina, no Levante. Análises tipológicas e iconográficas mostram, inclusive, que essas importações não eram movidas apenas por agentes terceiros, mas também por lacônios emigrados para regiões como Cirene e Tocra, no norte da África, Samos, na costa da Ásia Menor, e para as colônias da Magna Grécia (cf. COUDIN, 2009).

Em resumo, valendo-se do que sabemos sobre a tradição das máscaras de terracota no Mediterrâneo e, a menos que as máscaras de Orthia sejam um fenômeno espontâneo local, independente de influências externas (o que não creio ser o caso), ainda é extremamente difícil identificar uma única fonte de influência. Resta-nos apenas supor que as máscaras escavadas no santuário de Orthia sejam produtos da filtragem (primária ou secundária), por parte dos espartanos, de vários elementos pré-existentes de uma tradição já longeva e disseminada no Mediterrâneo. Tal tradição viajava pelos mesmos espaços que as cerâmicas lacônias, que os próprios lacônios, assumindo uma multiplicidade de formas e variações em cada costa em que aportava. ${ }^{14}$ Nesse sentido, temos novamente uma Esparta aberta a influências estrangeiras, talvez provenientes de mais de uma fonte, mas também interessada na adequação de tais elementos às demandas e preferências locais.

\section{A Esparta de Licurgo e o Oriente}

Vimos que a Esparta dos séculos VII e VI sofreu de fato algum nível de influência do Oriente Próximo, mas tanto por meio de intermediários quanto filtrando ou modificando tradições para que se ajustassem ao contexto local. As fontes nem sempre permitem traçar as origens exatas de tais influências, e estudos mais detalhados (que transbordariam os

\footnotetext{
${ }_{14}$ Um exemplo dessa multiplicidade de variações é o da ilha de Chipre, onde as máscaras se amalgamam a rituais com máscaras pré-existentes. Ver Averett (2015).
} 
limites desse artigo) são ainda necessários. Ainda assim, creio ser possível passar para o último tópico proposto: verificar se esse padrão se repete na Esparta posterior à Reforma de Licurgo.

Como já foi dito, essa Esparta geralmente é avaliada apenas pelas fontes literárias disponíveis, sendo caracterizada como extremamente fechada para influências externas. Já adianto que não será parte do argumento aqui desenvolvido que tal posicionamento dos espartanos não tenha existido no que tange a elementos culturais estrangeiros, fossem eles do Oriente ou de outras póleis gregas. Nem mesmo que ele seja baseado unicamente em exageros contemporâneos à Esparta do Período Clássico (Tucídides, 1, 71, 2-3) ou em reconstruções posteriores. Esses problemas, que compõem a chamada "Miragem Espartana" (cf. OLLIER, 1933), distorcem nossa visão sobre vários aspectos da sociedade espartana antiga (dentre os quais não excluo o ponto aqui discutido), mas também não devem, por sua vez, serem exacerbados a ponto de negar qualquer validade das fontes que possuímos sobre ela. Sabendo disso, creio ser possível afirmar que, até certo nível, a Esparta do final do século VI até o século IV assumia, em níveis variados, uma posição protetiva em relação aos nómoi estabelecidos por Licurgo. Essa posição, entretanto, não era totalitária: ela permitia aos espartanos transitar por vários contextos externos a Esparta (inclusive no Oriente) sem perder sua "essência" espartana. Pretendo mostrar que isso também valia para a parte interna de Esparta, isto é, que mesmo elementos estrangeiros eram ali recebidos, mas de modo a não permitir que essa mesma "essência" fosse descaracterizada.

Um dos exemplos mais citados pelas fontes e pela bibliografia dessa recepção é a adoção, em Esparta, da phoinikís, o manto tingido de púrpura usado durante embates militares - tanto por conta de sua aparência "masculina" quanto por sua utilidade em esconder o sangue escorrido de eventuais ferimentos (cf. CARTLEDGE, 1977, n. 38 para as fontes). $O$ próprio termo phoinikís, que faz referência justamente à cor que a caracterizava, traz em sua etimologia a origem fenícia de sua produção. A tinta produzida pela pesca e processamento de moluscos marinhos (o murex trunculus ou brandaris) era algo dispendioso, de modo que foi tida, não só em Esparta, como símbolo da distinção social dos que a utilizavam em suas vestes (REINHOLD, 1970). No que tange ao seu uso em Esparta, ela é frequentemente conectada ao fato de que há inúmeras menções antigas à produção dessa tintura na costa do Golfo da Lacônia e na ilha de Cítera, ${ }^{15}$ o que levou muitos acadêmicos a considerarem esses dois locais como pontos de interface entre espartanos e fenícios - esses últimos teoricamente como responsáveis pela introdução,

\footnotetext{
${ }^{15}$ Ilha ao sul do Golfo da Lacônia, controlada por Esparta durante o século V (Tucídides, 4, 53, 1; ver fig. 1).
} 
e talvez comercialização, da tinta púrpura ali produzida. ${ }^{16}$ Somando esses dois aspectos - o uso tradicional da tinta púrpura por Esparta e a produção no sul da Lacônia e em Cítera - temos um quadro no qual Esparta teria se mantido autossuficiente mesmo no fornecimento de um commodity caro e cuja técnica de produção era em si estrangeira. Entretanto, há sérios problemas com essa interpretação.

Primeiramente, no que diz respeito à pesca e ao processamento do murex no sul da Lacônia, é necessário dizer que nenhuma fonte comprova que essa produção acontecia no Período Clássico. As fontes literárias que mencionam a importante produção lacônia da tinta púrpura são posteriores, dos séculos I e II d.C. (Pausânias, 3, 21, 6; Plínio, o Velho, Naturalis Historia, 9, 60; 35, 26). Além disso, as conchas dos moluscos utilizadas no processo não têm seu contexto de achado datado, de modo que seria ao menos extremamente inseguro, dada a questão das fontes literárias, supor que esse corresponde também ao Período Clássico (LENORMANT, 1881, p. 107; SCOUFOPOULOS; MCKERNAN, 1975 , p. 103). Quanto à ilha de Cítera, as conchas de murex identificadas em Kastri foram datadas da Idade do Bronze (HUXLEY, 1972, p. 36, n. 4). A única indicação sobre uma

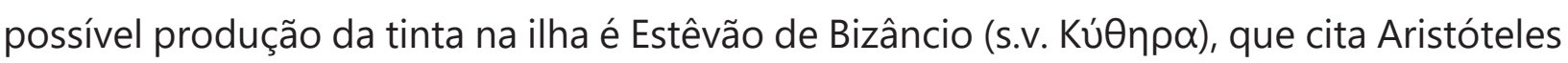
(fr. 521 Rose) ao dizer que Cítera era chamada de "Porfiroussa" ou "A Vermelha" - mas isso talvez no final do século IV, momento em que Esparta perde a força hegemônica que provavelmente baseava o controle da ilha. Dessa forma, em nenhuma das duas regiões há indícios conclusivos de produção da tinta púrpura durante o domínio espartano.

Ainda assim, Tucídides (4, 53, 2-3) nos fornece uma informação importante ao falar de Cítera, antes de sua conquista por parte dos atenienses de Nícias, em 424. Segundo ele, o interesse espartano na ilha se baseava também no fato de ela ser um ponto de parada para navios mercantes vindos do Egito e da Líbia. Aqui vale duas observações. A primeira é que Heródoto (1, 105, 3; cf. Paus., 3, 23, 1) afirma que o templo de Afrodite Urânia, em Cítera, teria sido fundado por fenícios. A segunda é que Neil Puckett (2012, p. 33; 54-55; 67; 117-118) mostrou recentemente que essa rota Creta/Egeu-Líbia-Egito provavelmente seguia condições climáticas e naturais (como a direção de ventos e correntes importantes) propícias paro o uso fenício, principalmente em seus caminhos de retorno ao Mediterrâneo ocidental pela costa do norte da África.

Levando tais elementos em conta, portanto, creio ser possível que Esparta, ciente de sua demanda de um commodity que ainda não era produzido localmente, tenha mantido algum interesse no acesso que Cítera fornecia a redes de comércio mediterrânicas mais

\footnotetext{
${ }^{16}$ Ver, por exemplo, Scoufopoulos; Mckernan (1975, p. 103); Cartledge (2002, p. 156-157). Banou (1996, p. 69) indica que as conchas de murex eram encontradas em Palaiókastro, sítio micênico na costa oeste do Cabo Malea. Sobre as conchas de murex encontradas em Ágios Stéfanos, na costa leste, ver Duhig et al. (2008, p. 522).
} 
amplas. Obviamente, é impossível que esse interesse, que chegava ao ponto de se indicar anualmente um oficial específico para a ilha - o kytherodikes (cf. Tuc., 4, 53, 1), algo sem paralelo em toda a Lacônia -, fosse devido unicamente à demanda da púrpura fenícia. Mas, mesmo assim, temos um quadro que mimetiza muito bem aquele observado em relação aos marfins e máscaras arcaicas. Esparta coloca um produto estrangeiro, provavelmente ainda não fabricado localmente, no seio de suas tradições, isso enquanto mantém uma distância estratégica dos agentes responsáveis por seu suprimento - afinal de contas, Cítera ainda permanecia uma ilha.

\section{Conclusão}

Foram três os estudos de caso aqui apresentados que, apesar de suas especificidades, revelaram um quadro relativamente homogêneo em relação ao contato mantido entre Esparta e elementos culturais originariamente fenícios. Vimos que os marfins dedicados no santuário de Ártemis Orthia entre os séculos VIII e VII foram, em primeiro lugar, adotados já em uma forma mediada, provavelmente pelos cretenses, isso antes de serem produzidos de acordo com o estilo local. Ou seja, a tradição dos objetos em marfim não foi diretamente para Esparta, mas enraizou-se ali em um segundo momento de sua transição dos fenícios para o Egeu. É esse momento que teria produzido, por sua vez, a demanda dos artesãos locais pela matéria-prima ao invés de por produtos acabados e, assim, uma provável conexão mais próxima com as redes mediterrânicas.

Ainda que o fornecimento de marfim tenha cessado na primeira metade do século VI, a presença lacônia no Mediterrâneo se mostra mais forte, tanto por meio das cerâmicas encontradas fora do Peloponeso quanto pelos objetos estrangeiros adotados/adaptados às demandas locais. As máscaras de terracotta dedicadas também no santuário de Orthia deixam isso claro. Dentre os vários elementos de uma tradição "púnico-mediterrânica", as máscaras espartanas são moldadas em formas e estilos (e provavelmente usos) idiossincráticos, claramente afastando-se dos desenvolvimentos estilísticos das máscaras fenícias encontradas por todo o Mediterrâneo. Temos, portanto, mais uma adaptação extremamente seletiva de elementos estrangeiros, "domesticados" de acordo com as demandas espartanas.

Por fim, lidamos com os phoinikídes, os mantos espartanos tingidos pela púrpura fenícia desde o Período Clássico. Vimos que, ao contrário do que parece, nada indica conclusivamente que as costas nas vizinhanças do Golfo da Lacônia produziam a tinta durante o Período Clássico - provavelmente Cítera tinha uma produção significativa, mas já na segunda metade do século IV, quando não é mais seguro dizer que Esparta mantinha 
algum controle sobre ela. No lugar disso, é mais plausível que Esparta se baseasse no comércio, talvez fenício, que cruzava o Mediterrâneo do Egeu para a Líbia, e aportava em Cítera no caminho. De novo vemos o quadro já delineado se mostrar: a púrpura, um elemento de ostentação em outras póleis, é adotada em Esparta e recebe inclusive um lugar entre as tradições locais, mas seguindo demandas específicas. Ao contrário da ostentação, a púrpura passa a caracterizar o uniforme do cidadão espartano e seu papel guerreiro em meio ao coletivo políade, isso enquanto é adquirida em uma ilha, fora da Lacônia - onde outros elementos culturais estrangeiros, talvez considerados "indesejados", poderiam ser mantidos sem grandes prejuízos às leis de Licurgo.

Sendo assim, é necessário algum cuidado ao falar da relação entre Esparta e o Oriente Próximo. Vários indícios deixam claro o contato entre Esparta e os produtos fenícios que viajavam por todo o Mediterrâneo, mas, ainda assim, há limites para a conectividade presumível disso. Respondendo à primeira pergunta aqui proposta, sobre a natureza das conexões entre Esparta e o Oriente Próximo, a amostra que tomamos revela que, para as demandas espartanas, talvez uma relação direta e massiva com os centros produtores das tradições que ali aportavam não fosse uma prioridade. O próprio ímpeto de adequar tais tradições aos gostos e usos locais talvez seja um indício que o interesse espartano não estava em se estabelecer ou disputar a posição de centro mediterrânico. A "calmaria" posterior à conquista definitiva da Messênia, talvez na segunda metade do século VII, foi seguida por outras preocupações. Temos, por exemplo, a expansão (fracassada) em direção a Tegeia e o estabelecimento de uma posição de dominância naquilo que viria a ser a Liga do Peloponeso (cf. Her., 1, 66-68), bem como as reverberações helênicas das Guerras Persas. Talvez os olhares espartanos estivessem mais voltados para dentro da Hélade do que para fora dela, mais preocupados com a construção de sua própria identidade e com a solidificação de uma posição segura em meio a uma série de disputas regionais.

Por outro lado, e respondendo à segunda pergunta formulada (sobre a concentração das conexões espartanas com o Oriente Próximo no Período Arcaico), não creio que seja plausível o fechamento absoluto da Esparta de Licurgo ao mundo externo. Ao invés disso, acredito que as amostras aqui tomadas nos permitam ver uma continuidade. A permeabilidade não-absoluta com o mundo externo à Lacônia, ainda que possa ter aumentado no século VI, permanece por todo o período aqui analisado, sem interrupções brutais que denunciem o advento dos nómoi de Licurgo.

Em uma época como a atual, onde a conectividade é quase algo dado, é necessário não esquecer que também ela serve a interesses específicos, e que nem sempre esses interesses apontam na direção da integração completa entre dois grupos. Não nego aqui a clara influência que os habitantes do Levante, do norte da Síria, Chipre, Samos ou mesmo 
Líbia tiveram na construção de Esparta e dos espartanos. Inclusive, se avançássemos na história da cidade, veríamos o quão essencial os persas foram para que Esparta atingisse (e mantivesse) o auge de sua hegemonia (cf. LEWIS, 1977; COZZOLI, 1984; STRONK, 19901). Na verdade, apenas enuncio que mesmo conexões claras como as vistas aqui precisam ser analisadas em suas especificidades, pois nem sempre a integração total é vantajosa para seus participantes.

De qualquer forma, o exposto aqui não chega nem perto de esgotar o tópico e/ou prover uma resposta duradoura para os questionamentos levantados. Ao invés disso, que o leitor tenha esse artigo como um convite à reflexão - talvez, na melhor das hipóteses, como uma base sobre a qual seja possível construir interpretações ainda mais sólidas.

\section{Referências}

\section{Documentação textual}

HERODOTUS. The Persian Wars. English translation by A. D. Godley. Cambridge: Harvard University Press, 1920. v. 1.

HERODOTUS. The Persian Wars. English translation by A. D. Godley. Cambridge: Harvard University Press, 1921. v. 2.

PAUSANIAS. Description of Greece: books 1-2. English translation by W. H. S. Jones. Cambridge: Harvard University Press, 1918. v. 1.

PLINY. Natural History: books 33-35. English translation by H. Rackham. Cambridge: Harvard University Press, 1940. v. 9.

PLINY. Natural History: books 8-11. English translation by H. Rackham. Cambridge: Harvard University Press, 1940. v. 3.

THUCYDIDES. History of the Peloponnesian War. English translation by C.F. Smith. Cambridge: Harvard University Press, 1919. v. 1.

THUCYDIDES. History ofthe Peloponnesian War. English translation by C.F. Smith. Cambridge: Harvard University Press, 1920. v. 2.

\section{Obras de apoio}

AFFANNI, G. Ivory sphinxes of North Syrian tradition: the flame and frond School. In: CECCHINI, S. M.; MAZZONI, S.; SCIGLIUZZO, E. (Ed.). Syrian and Phoenician ivories of the First Millennium BCE. Pisa: ETS, 2009, p. 171-185. 
AVERETT, E. W. Masks and ritual performance on the Island of Cyprus. American Journal of Archaeology, v. 119, n. 1, p. 3-45, 2015.

BANOU, E. Beitrag zum studium lakoniens in der mykenischen zeit. Munique: Tuduv Verlag, 1996.

BOARDMAN, J. Artemis Orthia and chronology. The Annual of the British School at Athens, v. 58, p. $1-7,1963$.

BURKERT, W. The Orientalizing Revolution: near eastern influence on Greek culture in the Early Archaic Age. Cambridge: Harvard University Press, 1992.

ÇAKIRLAR, C.; IKRAM, S. When elephants battle, the grass suffers: power, ivory and the Syrian elephant. Levant, v. 48, n. 2, p. 167-183, 2016.

CALAMA, C. Choruses of young women in Ancient Greece. Lanham: Rowman \& Littlefiel Publishers, 1997.

CAMPANELLA, L. Matrici fittili: coroplastica e altri materiali. In: BONETTO, J.; FALEZZA, G.; GHIOTTO, A. R. (Ed.). Nora: Il foro romano. Storia di un'area urbana dall'Età Fenicia alla Tarda Antichità. Padova: Italgraf, 2009, p. 525-538.

CARTER, J. B. Greek ivory carving in the Orientalising and Archaic Periods. New York: Garland, 1985.

CARTLEDGE, P. Hoplites and heroes: Sparta's contribution to the technique of ancient warfare. The Journal of Hellenic Studies, v. 97, p. 11-27, 1977.

CARTLEDGE, P. Sparta and Lakonia: a regional history 1300-362 BC. London: Routledge, 2002.

CAVANAGH, W. G.; GALLOU, C.; GEORGIADIS, M. (Ed.). Sparta and Laconia: from Prehistory to Pre-Modern. London: The British School at Athens, 2009.

CAVANAGH, W. Sparta and Laconia. In: LEMOS, I. S.; KOTSONAS, A. (Ed.). A Companion to the Archaeology of Early Greece and the Mediterranean. Hoboken: Wiley Blackwell, 2020, p. 649-670.

COUDIN, F. Les laconiens et la méditerranée à l'Époque Archaïque. Naples: Centre Jean Bérard, 2009.

COZZOLI, U. Sparta e la Persia nel conflitto marittimo contro la Lega Delio-Attica. In: LANZILLOTA, E. (Ed.). Problemi di storia e cultura spartana. Roma: Giorgio Bretschneider, 1984, p. 11-28.

DAWKINS, R. M. (Ed.). The Sanctuary of Artemis Orthia at Sparta. London: The British School at Athens, 1929b.

DAWKINS, R. M. The History of the Sanctuary. In: DAWKINS, R. M. (Ed.). The sanctuary of Artemis Orthia at Sparta. London: British School at Athens, 1929a. p. 1-51. 
DE MIROSCHEDJI, P. Far'ah, tell el-(north): Neolithic Period to Middle Bronze Age. In: STERN, E. (Ed.). The new encyclopedia of archaeological excavations in the Holy Land. Jerusalem: The Israel Exploration Society, 1993, p. 433-438. v. 2.

DICKINS, G. Ivory and Bone. In: DAWKINS, R. M. (Ed.). The Sanctuary of Artemis Orthia at Sparta. London: The British School at Athens, 1929, p. 203-248.

DICKINS, G. The Masks. In: DAWKINS, R. (Ed.). The Sanctuary of Artemis Orthia at Sparta. London: The British School at Athens, 1929, p. 163-186.

DOUGHERTY, C.; KURKE, L. Introduction: the cultures within Greek culture. In: DOUGHERTY, C.; KURKE, L. (Ed.). The cultures within ancient Greek culture: contact, conflict, collaboration. Cambridge: Cambridge University Press, 2003, p. 1-19.

DUHIG, C. et al. The Human and other organic remains. In: TAYLOUR, W. D.; JANKO, R. (Ed.). Ayios Stephanos: excavations at a Bronze Age and medieval sttlement in south Laconia. London: The British School at Athens, 2008, p. 485-525.

EDER, B. Argolis, Lakonien, Messenien vom ende der Mykenischen Palastzeit bis zur Einwanderung der Dorier. Vienna: Austrian Academy of Sciences Press, 1998.

EHRENBERG, V. From Solon to Socrates: Greek history and civilization during the $6^{\text {th }}$ and $5^{\text {th }}$ Centuries B.C. London: Methuen \& Co., 2011.

FELDMAN, M. H. Houses of ivory: the consumption of ivories in the Iron Age Levant. Altorientalische Forschungen, v. 42, n. 1, p. 97-111, 2015.

FIGUEIRA, T. J. Xenelasia and social control in classical Sparta. The Classical Quarterly, v. 53, n. 1, p. 44-74, 2003.

FRAGKOPOULOU, F. Lakonia and Samos during the Early Iron Age: a revised look the Messenian war dates. In: STAMPOLIDIS, N. CHR.; KANTA, A.; GIANNIKOURI, A. (Ed.). Athanasia: the earthly, the celestial and the underlworld in the Mediterranean from

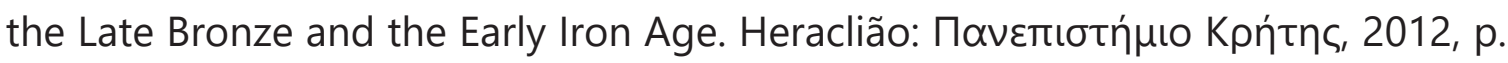
103-110.

HALL, J. M. Ethnic Identity in Greek Antiquity. Cambridge: Cambridge University Press, 1997.

HERRMANN, G.; LAIDLAW, S.; COFFEY, H. Ivories from the north West Palace (1845-1992): ivories from Nimrud VI. London: British Institute for the Study of Iraq, 2009.

HOLLADAY, A. J. Spartan austerity. The Classical Quarterly, v. 27, p. 111-126, 1977.

HUXLEY, G. L. The History and topography of ancient Kythera. In: COLDSTREAM, J. N.; HUXLEY, G. L. (Ed.). Kythera: excavations and studies conducted by the University of Pennsylvania Museum and the British School at Athens. London: Faber, 1972, p. 33-40. 
KOPANIAS, K. Some ivories from the geometric stratum at the sanctuary of artemis Orthia, Sparta: interconnections between Sparta, Crete and the Orient during the Late Eighth Century BC. In: CAVANAGH, W. G.; GALLOU, C.; GEORGIADIS, M. (Ed.). Sparta and Laconia: from Prehistory to Pre-Modern. London: The British School at Athens, 2009, p. 123-131.

LENORMANT, F. La Grande-Grèce: paysages et histoire. Paris: A. Lévy, 1881.

LEWIS, D. M. Sparta and Persia. Leiden: Brill, 1977.

MALLET, J. Tell el-Fâr'ah II: le Bronze Moyen. Stratigraphie des vestiges du Bronze Moyen II (Ire Moitié du Ile Millénaire av. J.-C.) dans les chantiers principaux II nord et IV. Paris: Recherche sur les Civilisations, 1987.

MARANGOU, E.-L. Lakonische elfenbein: und beinschnitzereien. Tubinga: Wasmuth, 1969. MARKOE, G. E. Phoenicians. Berkeley: University of California Press, 2000.

MORRIS, S. P. Daidalos and the origins of Greek art. Princeton: Princeton University Press, 1992.

NAFISSI, M. Sparta. In: RAAFLAUB, K. A.; VAN WEES, H. (Ed.). A companion to archaic Greece. Chichester: Blackwell, 2009, p. 117-137.

NIEMEYER, H. G. Figürliche Terrakotten. In: NIEMEYER, H. G. et al (Ed.). Karthago: die ergebnisse der Hamburger Grabung unter dem Decumanus Maximus. Mainz am Rhein: Hamburger Forschungen zur Archäologie, 2007, p. 758-764.

OLLIER, F. Le Mirage Spartiate. Paris: De Boccard, 1933.

ORSINGHER, A. Listen and protect: reconsidering the grinning masks after a recent find from Motya. Vicino Oriente, v. 18, p. 145-171, 2014.

ORSINGHER, A. Ritualized faces: the masks of the Phoenicians. In: BERLEJUNG, A.; FILITZ, J. E. (Ed.). The physicality of the other: masks form the Ancient Near East and the Eastern Mediterranean. Tübingen: Mohr Siebeck, 2018, p. 263-303.

PIPILI, M. Archaic Lakonian vase-painting: some iconographic considerations. In: CAVANAGH, W. G.; WALKER, S. E. C. (Ed.). Sparta in Lakonia. London: The British School at Athens, 1998, p. 82-96.

PUCKETT, N. N. The Phoenician trade network: tracing a Mediterranean exchange system. 2012. 319 f. Dissertação (Mestrado em Artes) - Texas A\&M University, Texas, 2012. REINHOLT, M. History of purple as a status symbol in Antiquity. Bruxelas: Latomus, 1970. RICHER, N. Sparte: cité des arts, des armes et des lois. Perrin: Paris, 2018. ROSENBERG, J. L. The Masks of Orthia: form, function and the origins of theatre. The Annual of the British School at Athens, v. 110, n. 2, p. 247-261, 2015. 
SCHUBART, H. Morro de la Mezquitilla: Informe preliminar sobre la campaña de excavaciones de 1981 em el Morro de la Mezquitilla, cerca de la Desembocadura del Río Algarrobo. Noticiario Arqueológico Hispánico, v. 19, p. 85-101, 1984.

SCOUFOPOULOS, N. C.; MCKERNAN, J. G. Underwater survey of sncient Gytheion, 1972. The International Journal of Nautical Archaeology and Underwater Exploration, v. 4, n. 1, p. 103-116, 1975.

SHIPLEY, G. A History of Samos: 800-188 BC. Oxford: Clarendon Press, 1987.

SHIPLEY, G. Early Hellenistic Sparta: changing modes of interaction with the wider world? In: KALTSAS, N. (Ed.). Athens-Sparta: contributions to the research on the history and archaeology of two city-states. New York: Alexander S. Onassis, 2009, p. 55-60.

ST. CLAIR, A. Carving as craft: Palatine East and the Greco-Roman bone and ivory carving tradition. Baltimore: The Johns Hopkins University Press, 2003.

STARR, C. G. The credibility of early Spartan history. In: WHITBY, M. (Ed.). Sparta. New York: Routledge, 2002, p. 26-43.

STIBBE, C. M. Lakonische keramik aus dem heraion von Samos. Mitteilungen des deutschen Archaologischen Instituts, v. 112, p. 25-142, 1997.

STRONK, J. P. Sparta and Persia: 412-386. Talanta, v. 22-23, p. 117-136, 1990-1.

STUBBS, H. W. Spartan austerity: a possible explanation. Classical Quarterly, v. 44, p. 3237, 1950.

SUDDABY, T. A. Masks, maidens and men: gender and interpretations of the cult of Artemis Orthia at Sparta. 2017. 78 f. Dissertação (Mestrado em Artes) - University of Alberta, Edmonton, 2017.

SUTTER, C. E. Classifying Iron Age Levantine ivories: impracticalities and a new approach. Altorientalische Forschungen, v. 42, n. 1, p. 31-45, 2015.

WINTER, I. J. Is there a south Syrian style of ivory carving in the early First Millennium B.C.? Iraq, v. 43, n. 2, p. 101-130, 1981.

WINTER, I. J. Phoenician and north Syrian ivory carving in historical context: questions of style and distribution. Iraq, v. 38, n. 1, p. 1-22, 1976. 